\title{
Bronchodilator effects of clemastine, ipratropium bromide, and salbutamol in preschool children with asthma
}

\author{
R C GROGGINS, A D MILNER, AND G M STOKES \\ Department of Child Health, Medical School, Queen's Medical Centre, Nottingham
}

SUMmARY The bronchodilator activity of nebulised salbutamol, ipratropium bromide, clemastine, and a placebo was studied in 14 asthmatic children aged between 3 and 5 years. Changes in lung function were monitored by measuring peak expiratory flow rate and total respiratory resistance using a modification of the forced oscillation technique. Ipratropium bromide produced a degree of bronchodilatation similar to that of salbutamol, but the bronchodilator activity of clemastine was not appreciably better than for the placebo.

Salbutamol inhaled from a nebuliser is an effective bronchodilator in children with asthma over age 18 months. ${ }^{1}$ Nevertheless, some asthmatic children continue to have severe symptoms despite nebulised treatment at home, and acute severe asthma remains a common indication for admission to hospital. For these reasons it is justified to investigate the therapeutic effects of other forms of treatment.

It has been shown that an antihistamine, chlorpheniramine, is an effective bronchodilator if inhaled by asthmatic schoolchildren but it is too irritant for general clinical use. ${ }^{2}$ An alternative antihistamine, clemastine, appears to be superior from this point of view but has not been evaluated in childhood asthma. ${ }^{3}$

Anticholinergic drugs are effective in older children and adults with asthma but there is no information on their use in the preschool child. A new anticholinergic agent, ipratropium bromide, is now available and is said to be preferable to atropine, because it produces less tachycardia and a smaller reduction in sputum flow. ${ }^{4}$ We have therefore compared the bronchodilator properties of inhaled salbutamol, clemastine, and ipratropium bromide in a group of young asthmatic children to find out if these other drugs have a place in the management of preschool asthma.

\section{Patients}

Fourteen children ( 9 boys and 5 girls) aged 3 years 2 months to 5 years 5 months (mean 4 years 1 month) were studied. They had suffered from asthma for between 1 year 4 months and 4 years 9 months (mean 2 years 8 months). Thirteen children were between the 3rd and 97th centiles for height, and one child was just below the 3rd centile for both height and weight. ${ }^{5}$ Eight children had a family history of asthma and 5 suffered from eczema. The 2 children on whom skin tests had been performed showed multiple positive responses to common antigens. Ten children had required hospital admissions (range 1 to 9), and 8 had been treated with courses of oral steroids although none was receiving such drugs at the time of testing. All the children required regular treatment for their asthma such as-sodium cromoglycate (in 9), beclomethasone diproprionate powder (in 5), theophylline (in 2), and salbutamol orally or inhaled (in all 14). Seven children had nebulisers at home. All the children had previously had tests of lung function and were accustomed to the procedures. Fully informed parental consent was obtained on all occasions and the mothers were present during each test session.

\section{Method}

Apparatus. Two systems were used to assess changes in lung function.

\section{Wright's low range peak flow meter}

This provides reproducible results of peak expiratory flow rate (PEFR) down to age $2 \frac{1}{2}$ years. ${ }^{6}$

\section{A modification of the forced oscillation technique}

The technique is based on the principle that when a 
sine wave flow oscillation is applied to the respiratory system at the resonant frequency, the impedence to the oscillatory flow is due solely to the total respiratory resistance $\left(R_{T}\right)$, since at resonance the elastic and inertial components are of equal magnitude and opposite in sign. The apparatus has been described in detail in a previous article. ${ }^{7}$

Procedure. The children were studied on four occasions, always at the same time of day and generally over a period of not more than 2 weeks. All medication was stopped for at least 12 hours before each test session. On arrival each mother was questioned about the child's recent health, and then the clinical examinations were performed. Baseline measurements of heart rate, PEFR (best of three attempts), and $R_{T}$ were recorded. After resting for 15 minutes all investigations were repeated. The children then inhaled solutions of the drugs from a Pari nebuliser. The drug regimens used were salbutamol $5 \mathrm{mg}$, clemastine $1 \mathrm{mg}$, ipratropium bromide $250 \mu \mathrm{g}$, or saline placebo. All drugs were made up in $2 \mathrm{ml}$ of saline and the doses used are about equivalent to half of the normal adult dose (Table). Changes in lung function were assessed serially over 30 minutes, when second inhalations were administered. These second treatments consisted of salbutamol $5 \mathrm{mg}$ in $2 \mathrm{ml}$ of saline, unless the child had already received this drug in which case the placebo was given. Lung function was assessed after a further 10 minutes. All treatments were administered double-blind and in a random order.

\section{Results}

Changes in PEFR and $R_{T}$ are shown in Figs 1 and 2. Results are expressed as percentages of PEFR and $\mathbf{R}_{\mathbf{T}}$ predicted from the children's heights. ${ }^{6} 8$ There was no significant difference in the initial values between the four groups, although the children tended to be at their worst when attending on the placebo day. When salbutamol was given as the first inhalation, there was a considerable improvement in PEFR and $R_{T}$ at 2 minutes. Between 2 and 30 minutes there was a small further improvement but no change after the inhalation of a saline

\section{Table Treatment regimens used}

\begin{tabular}{lll}
\hline Treatment & Inhalation \\
\cline { 2 - 3 } & $1 s t$ & $2 n d$ \\
\hline A & Salbutamol $5 \mathrm{mg}$ & Placebo \\
B & Clemastine $1 \mathrm{mg}$ & Salbutamol $5 \mathrm{mg}$ \\
C & Ipratropium bromide $250 \mu \mathrm{gg}$ & Salbutamol $5 \mathrm{mg}$ \\
D & Placebo & Salbutamol $5 \mathrm{mg}$ \\
\hline
\end{tabular}

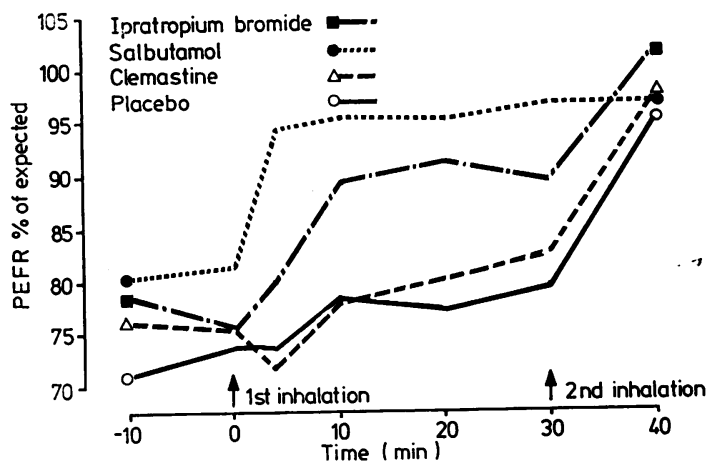

Fig. 1 Mean peak expiratory flow rate expressed as a percentage of expected, before and after the administration of ipratropium bromide, salbutamol, clemastine, or placebo (1st inhalation). The second inhalation contained nebulised salbutamol except when this had been given as the first treatment, in which case saline alone was inhaled.

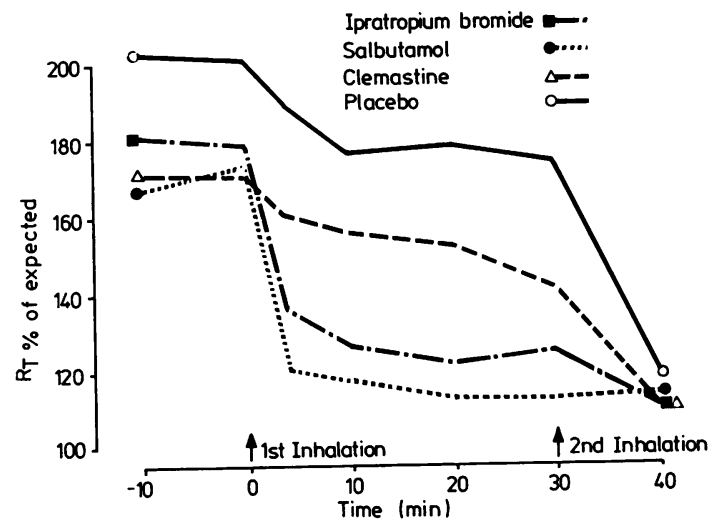

Fig. 2 Mean total respiratory resistance expressed as a percentage of expected, before and after the administration of ipratropium bromide, salbutamol, clemastine, or placebo (1st inhalation). The second inhalation contcined nebulised salbutamol except when this had been given as the first treatment, in which case saline alone was inhaled.

placebo. After treatment with ipratropium bromide appreciable bronchodilatation also took place. Changes at 2 minutes were less pronounced than with salbutamol but between 10 and 30 minutes later the improvement produced by the two drugs was very similar. When salbutamol was inhaled $\mathbf{3 0}$ minutes after ipratropium bromide, there was a further improvement in lung function of about $10 \%$. When the post-treatment measurements were expressed as a percentage change from the initial results and 
analysed using Student's $t$ test, there were significant differences in $\mathbf{R}_{\mathbf{T}}$ between the placebo and both salbutamol and ipratropium bromide at all times between 2 and 30 minutes $(P<0.01$ to $<0.001)$. Improvements in PEFR were significantly better than for the placebo after both these drugs between 2 and 20 minutes $(P<0.05)$ but not at 30 minutes, when there was a greater scatter of results. The changes in lung function after the inhalation of clemastine closely matched those after placebo. The inhalation of salbutamol in children who had already received either clemastine or the placebo, led to results in lung function tests similar to those seen after the other two drug combinations. The mean PEFR approached $100 \%$ and the $R_{T}$ fell to between 110 and $118 \%$ of the predicted value.

No significant side effects were observed after any of the inhalations. All the drugs were almost tasteless and no child coughed. Small increases in heart rate were noted, particularly after the salbutamol inhalation when there was an average rise of 10 beats a minute at 2 minutes. The other inhalations caused rises of up to 5 beats a minute.

\section{Discussion}

As seen in previous reports, the response to inhaled salbutamol was striking. ${ }^{179}$ The improvement in lung function after the inhalation of ipratropium bromide was equally impressive, although the response was a little slower. This is the first time that anticholinergic drugs have been shown to be effective in relieving bronchoconstriction in children below age 5 years. There was a small additional improvement after the second inhalation (salbutamol). These results suggest that ipratropium bromide may have a role in the management of preschool asthma, either alone or in combination with beta 2 adrenergic stimulants, and this drug certainly warrants further study. Ipratropium is believed to act mainly on the large airways, while beta stimulants relieve bronchoconstriction both in central and peripheral airways. ${ }^{10} 11$ Studies in animals have demonstrated a possible synergism between these two groups of drugs $^{12}$ and work in adult asthmatics shows an additive effect in some circumstances often with a prolonged effect. ${ }^{13} 14$

The response to clemastine was disappointing as this form of treatment did not appear to be in any way better than the placebo. These results are strikingly different from those of Nogrady et al. ${ }^{3}$ who found that the bronchodilator effect of clemastine was similar to that of salbutamol. Previous work ${ }^{2}$ from this department has shown that another antihistamine, chlorpheniramine, is effective in older asthmatic children. However, in the preschool child with recurrent wheezing attacks infection appears to be considerably more important than allergen in precipitating attacks and histamine may play a less important role in infection-induced bronchoconstriction. Further work is required to determine the age at which antihistamines work.

We thank the children and their parents for co-operation.

Financial support was provided by the Asthma Research Council.

\section{References}

1 Lenney W, Milner A D. At what age do bronchodilator drugs work? Arch Dis Child 1978; 53: 532-5.

2 Groggins R C, Milner A D, Stokes G M. The bronchodilator effects of chlorpheniramine in childhood asthma. Br J Dis Chest 1979; 73: 297-301.

3 Nogrady S G, Hartley J P R, Handslip P D J, Hurst N P. Bronchodilatation after inhalation of the antihistamine clemastine. Thorax 1978; 33: 479-82.

4 Lin M T, Lee-Hong E, Collins-Williams C. A clinical trial of the bronchodilator effect of SCH 1000 aerosol in asthmatic children. Ann Allergy 1978; 40: 326-32.

5 Tanner J M, Whitehouse R H, Takaishi M. Standards from birth to maturity for height, weight, height velocity, and weight velocity: British children, 1965. Arch Dis Child 1966; 41: 454-71; 613-35.

6 Milner A D, Ingram D. Peak expiratory flow rates in children under five years of age. Arch Dis Child 1970; 45: 780-2.

7 Lenney W, Milner A D. Recurrent wheezing in the preschool child. Arch Dis Child 1978; 53: 468-73.

8 Cogswell J N. Forced oscillation technique for determination of resistance to breathing in children. Arch Dis Child 1973; 48: 259-66.

9 Groggins R C, Lenney W, Milner A D, Stokes G M. Efficacy of orally administered salbutamol and theophylline in pre-schoolchildren with asthma. Arch Dis Child 1980; 55: 204-6.

10 Hensley M J, O'Cain C F, McFadden E R, Jr, Ingram R H, Jr. Distribution of bronchodilatation in normal subjects: beta agonists versus atropine. J Appl Physiol (Respir Environ Exerc Physiol) 1978; 45: 778-82.

11 Thomson N C, Patel K R, Kerr J W. Sodium cromoglycate and ipratropium bromide in exercise-induced asthma. Thorax 1978; 33: 694-9.

12 Offermeier J. Synergistic effects of SCH 1000 and beta adrenergics on isolated organs (abstract). Postgrad Med $J 1975 ; 51$ : Supplement 7, 117.

13 Chamberlain D A, Muir D C F, Kennedy K P. Atropine methonitrate and isoprenaline in bronchial asthma. Lancet 1962; ii: 1019-21.

14 Pierce R J, Allen C J, Campbell A H. A comparative study of atropine methonitrate, salbutamol, and their combination in airways obstruction. Thorax $1979 ; 34$ : 45-50.

Correspondence to Dr A D Milner, Department of Child Health, Medical School, Queen's Medical Centre, Clifton Boulevard, Nottingham NG7 2UH.

Received 18 March 1980 